\title{
SIMSIA BICENTENARIALIS (COMPOSITAE-HELIANTHEAE) UNA ESPECIE NUEVA DEL CENTRO DE MÉXICO*
}

\author{
Jerzy Rzedowski y Graciela Calderón De Rzedowski**
}

Instituto de Ecología, A.C., Centro Regional del Bajío, Apdo. postal 386, 61600 Pátzcuaro, Michoacán, México

\section{RESUMEN}

Se describe como nueva y se ilustra Simsia bicentenarialis del noreste y centro de Querétaro y noreste de Guanajuato. La planta presenta semejanzas con algunas variedades de S. foetida (Cav.) S. F. Blake.

Palabras clave: Compositae, Heliantheae, México, Simsia, taxonomía.

\section{ABSTRACT}

Simsia bicentenarialis from northeastern and central Queretaro and northeastern Guanajuato is described as new and illustrated. It shows similarities with some varieties of S. foetida (Cav.) S. F. Blake.

Key words: Compositae, Heliantheae, Mexico, Simsia, taxonomy.

En el transcurso de la preparación del segundo fascículo de la Flora del Bajío y de regiones adyacentes, correspondiente a las Compositae-Heliantheae, los autores

\footnotetext{
* Trabajo realizado con apoyo económico del Instituto de Ecología, A.C. (cuenta 20006), del Consejo Nacional de Ciencia y Tecnología y de la Comisión Nacional para el Conocimiento y Uso de la Biodiversidad.

** Los autores agradecemos al Dr. José L. Panero la amabilidad de haber puesto a nuestra disposición las pruebas de imprenta del trabajo aún inédito.
} 
encontraron materiales de las siguiente especie, que aparentemente no corresponde a ningún taxon hasta ahora conocido.

Simsia bicentenarialis Rzed. \& Calderón, sp.n. Fig. 1.

Planta herbacea ad $2 \mathrm{~m}$ alta; caules erecti, dense hispido-pilosi pilis 2-3 $\mathrm{mm}$ longis et minute stipitato-glandulosi; folia infera vel interdum fere omnia opposita, cetera alterna, sessilia vel cum petiolo alato ad $4 \mathrm{~cm}$ longo, lamina deltoideoovata ad lanceolata, (3)6-14 cm longa, (1)2.5-11 cm lata, apice acuminata vel acuta, base rotundata ad truncata et abrupte decurrens, margine grosse serrata, trinervata, utrinque pilosa et minute glandulosa; capitula in catervis cymosis terminalibus aggregata, rare solitaria, pedunculis ad $20 \mathrm{~cm}$ longis; involucrum late campanulatum ad subhemisphaericum phyllariis 20-35 plerumque subaequalibus anguste lanceolatis vel linearibus 10-13 mm longis membranaceis, receptaculum convexum, paleis oblongis $10-11 \mathrm{~mm}$ longis; flosculi radii 12-15 steriles, ligulis oblongo-ellipticis 9-12 mm longis luteis pallidis; flosculi disci $80-125$, corollis 7-8 mm longis luteis; achenia oblanceolata tetragona ad biconvexa ca. $3 \mathrm{~mm}$ longa griseo-ningricantia glabra vel sparse glandulari-puberula epapposa.

Planta herbácea hasta de $2 \mathrm{~m}$ de alto; tallos erectos, simples o ramificados en la parte superior, de color pajizo o café, estriados, densamente híspido-pilosos con pelos pluricelulares erectos de 2 a $3 \mathrm{~mm}$ de largo entremezclados con numerosas glándulas estipitadas diminutas; hojas inferiores o a veces casi todas opuestas, por lo general predominando las alternas, en las opuestas con rebordes interpeciolares, sésiles o con peciolo por lo general alado hasta de $4 \mathrm{~cm}$ de largo, lámina deltoideovada a lanceolada, de (3)6 a $14 \mathrm{~cm}$ de largo, de (1) 2.5 a $11 \mathrm{~cm}$ de ancho, acuminada o aguda en el ápice, redondeada a truncada y abruptamente decurrente sobre el peciolo en la base, irregularmente serrada en el margen, trinervada, de textura membranácea, verde oscura en ambas superficies, más o menos densamente pilosa con pelos similares a los del tallo y además provista de numerosas glándulas diminutas, sésiles o cortamente estipitadas; cabezuelas dispuestas por varias en grupos cimosos terminales, en conjunto formando a menudo una panícula foliosa hasta de $50 \mathrm{~cm}$ de largo y $30 \mathrm{~cm}$ de diámetro, rara vez solitarias, pedúnculos hasta de $20 \mathrm{~cm}$ de largo; involucro ampliamente campanulado a subhemisférico, sus brácteas 20 a 35, dispuestas en 2 a 3 series de largo casi igual o a veces algunas de las interiores más cortas que las exteriores, angostamente lanceoladas o lineares, de 10 a $13 \mathrm{~mm}$ de largo, puntiagudas, verdes y de textura membranácea, con pubescencia 
Rzedowski y Calderón de Rzedowski: Simsia bicentenarialis, especie nueva de México

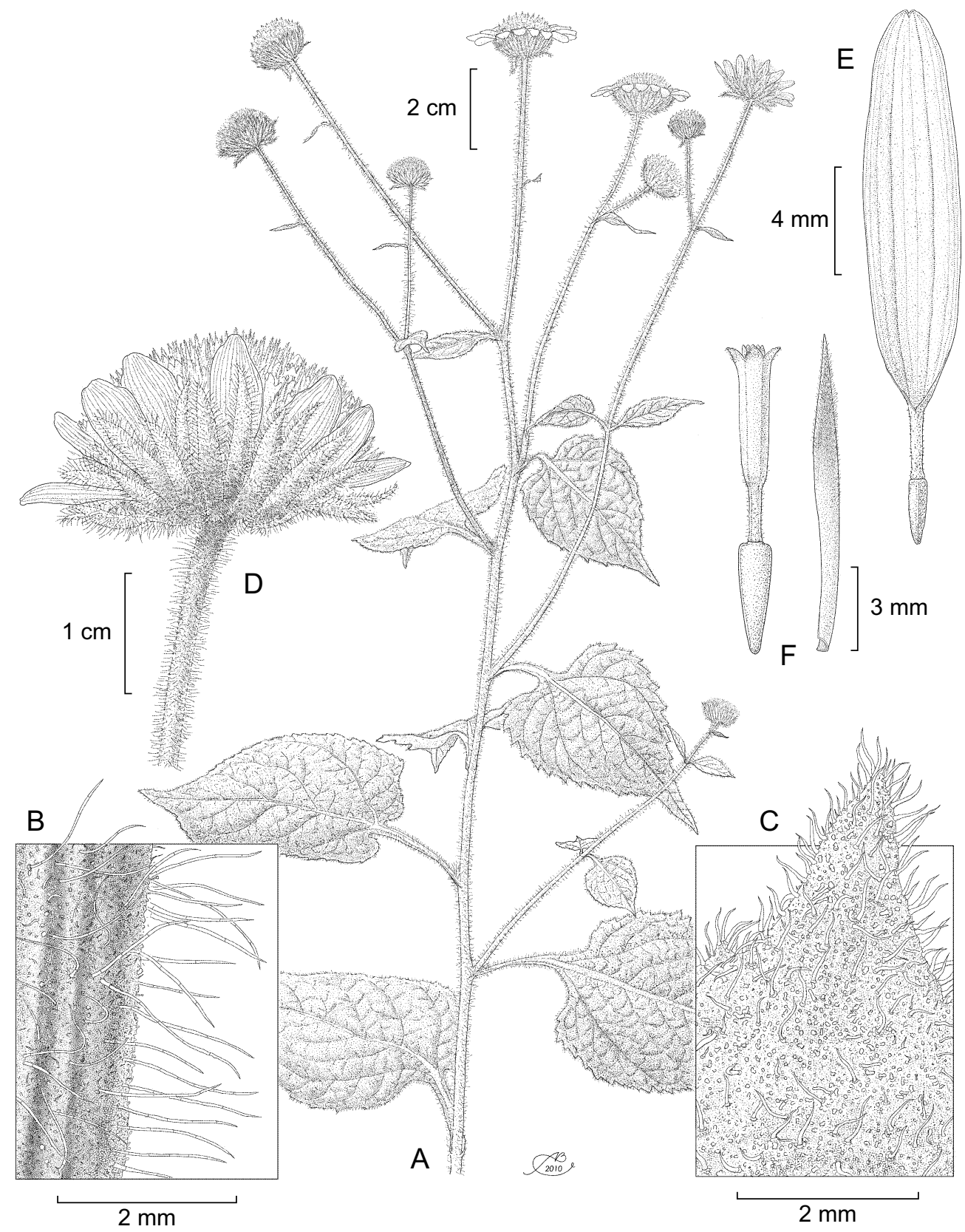

Fig. 1. Simsia bicentenarialis Rzed. \& Calderón. A. rama con hojas y cabezuelas; B. detalle de la pubescencia del tallo; C. detalle de la pubescencia de la hoja; D. cabezuela; E. flor ligulada; F. flor del disco y pálea. Ilustrado por Alfonso Barbosa. 
similar a la de las hojas en la superficie abaxial, receptáculo ligeramente convexo, páleas oblongas, de 10 a $11 \mathrm{~mm}$ de largo, atenuadas y puntiagudas en el ápice, con pubescencia similar a la de las hojas en la porción superior abaxial; flores periféricas 12 a 15, estériles, sus láminas oblongo-elípticas, de 9 a $12 \mathrm{~mm}$ de largo, amarillas pálidas con numerosas nervaduras moradas, finamente glanduloso-pubérulas por dentro, papilosas por fuera, sus ovarios lineares; flores del disco 80 a 125, sus corolas angostamente tubulosas, amarillas, de 7 a $8 \mathrm{~mm}$ de largo, de los cuales ca. $3 \mathrm{~mm}$ corresponden al tubo que es glanduloso-pubérulo y ca. $1 \mathrm{~mm}$ a los lóbulos que son papilosos por dentro e hispídulos por fuera, anteras de ca. $3 \mathrm{~mm}$ de largo, negruzcas, algo exsertas, ramas del estilo lineares, hispídulas en el ápice, provistas de apéndice agudo; aquenios oblanceolados, tetrágonos a biconvexos, de ca. $3 \mathrm{~mm}$ de largo, grisnegruzcos, glabros o muy esparcidamente glandular-pubérulos, vilano ausente.

Tipo: México, Querétaro, Sótano Pozo de la Peña, al W de San Antonio Tancoyol, municipio de Jalpan, bosque tropical caducifolio, alt. 880 m, 5.IX.1991, E. Carranza 3470 (IEB, isotipos por distribuirse).

Material adicional examinado: México, Guanajuato, Puerto El Gallo, $10 \mathrm{~km}$ al sureste de La Joya, municipio de Atarjea, bosque de pino, alt. 2100 m, 14.VIII.1988. E. Ventura y E. López 6498 (IEB). Querétaro, aprox. 3-5 km al SW de Río Blanco, municipio de Peñamiller, bosque de Pinus cembroides, alt. 1830-1950 m, 19.IX.1991, E. Carranza 3514 (IEB); $2 \mathrm{~km}$ al N de Mesa de León, municipio de Cadereyta, matorral desértico crasicaule, alt. 1800 m, 29.X.1991, V. M. Huerta B. 1293 (IEB).

El taxon parece representar un endemismo del centro-noreste de Querétaro y partes aledañas del noreste de Guanajuato. Cabría también esperar su presencia en sectores aledaños de Hidalgo. Prospera sobre suelos derivados de rocas calizas.

El material examinado no revela las partes inferiores de la planta, pero es probable que se trate de una especie anual.

En virtud de su involucro constituido por brácteas verdes de textura herbácea, sus flores liguladas estériles y sus aquenios tetrágonos o biconvexos, S. bicentenarialis pertenece al grupo reconocido por Blake (1918) como serie Grammatoglossae y ubicado por el mismo en el género Viguiera.

Varios autores, sin embargo, y en particular Spooner (1990) notaron que algunos de los componentes de la serie Grammatoglossae tienen más afinidad con Simsia que con las restantes especies de Viguiera. En este mismo contexto y como resultado de un estudio filogenético molecular (basado en la determinación de secuencias de 
ADN tanto nuclear como del cloroplasto) Schilling y Panero (en prensa) decidieron ampliar la circunscripción de Simsia para incluir a varias especies que en virtud de la forma de sus aquenios tenían y tendrían tradicional acomodo en Viguiera.

La especie nueva encuentra buen sitio en este nuevo concepto de Simsia en virtud de los ovarios lineares de las flores liguladas, de sus ramas de estilo puntiagudas y de la presencia de rebordes interpeciolares similares a una forma reducida de los discos (nodales) definidos por Spooner (op. cit.).

S. bicentenarialis podría vincularse con algunos de los componentes del complejo de S. foetida (Cav.) S. F. Blake (Spooner, 1990), en particular con las variedades foetida y megacephala (Sch. Bip. ex S. F. Blake) D. M. Spooner, en virtud de las características del involucro, de la pubescencia y del color de las lígulas, pero se distingue en la forma de las hojas, en la falta del vilano, así como en el grosor del aquenio, rasgo que tradicionalmente se empleaba para separar Simsia de Viguiera.

El nombre S. bicentenarialis alude y pondera la celebración en el año 2010 del ducentésimo aniversario del inicio de la lucha de la independencia de nuestro país.

\section{LITERATURA CITADA}

Blake, S. F. 1918. A revision of the genus Viguiera. Contr. Gray Herb. 54: 1-205.

Schilling, E. E. \& J. L. Panero (en prensa). Transfers to Simsia and descriptions of Davilanthus, a new genus of Asteraceae (Heliantheae). Brittonia.

Spooner, D. M. 1990. Systematics of Simsia (Compositae - Heliantheae). Syst. Bot. Monogr. 30: $1-90$. 